\title{
Erratum to: New results of positive solutions for the Sturm-Liouville problem
}

GC Yang ${ }^{*}$ and HB Feng

\section{"Correspondence:}

\section{gcyang@cuit.edu.cn}

College of Applied Mathematics, Chengdu University of Information

Technology, Chengdu, Sichuan 610225, P.R. China
Unfortunately, the original version of this article [1] contained an error. At the top of page 14, $\underline{w}$ in the following expression should be replaced by $\omega$, that is,

$$
p(t) z_{*}^{\prime}(t)=\frac{\mu_{1}\left(L_{\psi}^{\left(n_{0}\right)}\right)}{\Gamma} \begin{cases}\alpha \int_{\frac{1}{n_{0}}}^{1-\frac{1}{n_{0}}} \underline{w}_{1}(s) \psi(s) z_{*}(s) d s & \\ -\gamma \int_{\frac{1}{n_{0}}}^{t} \frac{w_{0}}{\Gamma}(s) \psi(s) z_{*}(s) d s, & 0 \leq t<1 / n_{0}, \\ +\alpha \int_{t}^{1-\frac{1}{n_{0}}} \underline{w}_{1}(s) \psi(s) z_{*}(s) d s, & 1 / n_{0} \leq t \leq 1-1 / n_{0}, \\ -\gamma \int_{\frac{1}{n_{0}}}^{1-\frac{1}{n_{0}}} \underline{w}_{0}(s) \psi(s) z_{*}(s) d s, & 1-1 / n_{0}<t \leq 1,\end{cases}
$$

should be

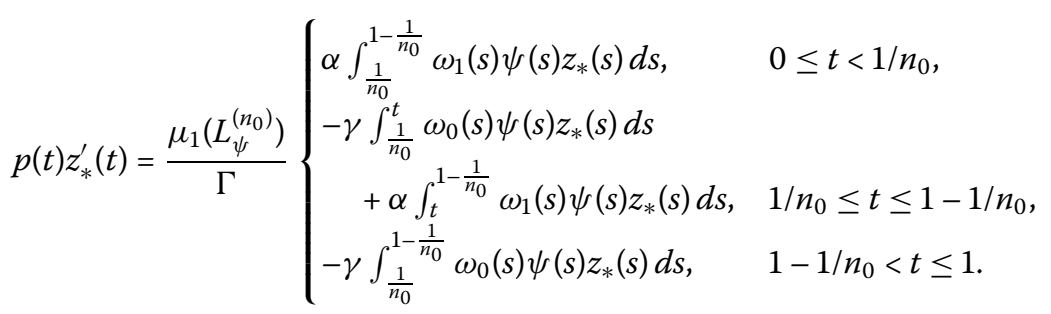

We would like to apologize for this error and for any inconvenience this may have caused.

Received: 21 March 2016 Accepted: 21 March 2016 Published online: 29 March 2016

\section{References}

1. Yang, GC, Feng, HB: New results of positive solutions for the Sturm-Liouville problem. Bound. Value Probl. 2016, 64 (2016). doi:10.1186/s13661-016-0571-1

(c) 2016 Yang and Feng. This article is distributed under the terms of the Creative Commons Attribution 4.0 International License (http://creativecommons.org/licenses/by/4.0/), which permits unrestricted use, distribution, and reproduction in any medium, provided you give appropriate credit to the original author(s) and the source, provide a link to the Creative Commons license, and indicate if changes were made. 